\author{
Sesilia Windy Carena ${ }^{1}$ dan Ratri Wulandari ${ }^{2}$ \\ Program Studi Desain Interior \\ Universitas Telkom \\ 'swcarena@yahoo.co.id \\ ${ }^{2}$ ratriwulandari@tcis.telkomuniversity.ac.id
}

\title{
EFEK PENCAHAYAAN BUATAN TERHADAP TAMPILAN KARYA DI ROEMAH SENI SARASVATI
}

\begin{abstract}
Abstrak: Galeri seni adalah ruangan atau gedung tempat memamerkan karya seni. Galeri merupakan tempat untuk kegiatan pameran yang bersifat hiburan, rekreasi dan media apresiasi dari berbagai seniman, baik lokal maupun asing. Penelitian ini dilakukan di Roemah Seni Sarasvati, Bandung, Jawa Barat, sebuah galeri yang berlokasi di Jl. Jendral Sudirman 137, Bandung, penelitian ini lebih mengacu kepada efek pencahayaan buatan terhadap tampilan karya di Roemah Seni Sarasvati. Roemah Seni Sarasvati merupakan proyek utama Sarasvati Arts Management yang dibangun dengan tujuan untuk memperkenalkan keragaman seni budaya. Pencahayaan terhadap karya seni di Roemah Seni Sarasvati terlihat gelap pada bagian karya seni lukisan dan pada area yang bukan karya seni seperti ruang tunggu atau jalan menuju ruang-ruang lainnya. Berbagai informasi mengatakan bahwa pencahayaan buatan lebih baik daripada pencahayaan alami karena pencahayaan buatan yaitu cahaya dari lampu tidak merusak karya seni yang ada daripada cahaya langsung dari sinar ultraviolet. Hal tersebut dapat dilakukan dengan pemberian cahaya buatan dengan tingkat keterangan cahaya tertentu untuk mengurangi radiasi sinar ultraviolet. Sebagian besar galeri seni, pencahayaan di semua daerah pameran dan daerah koleksi lain harus berpelindung UV dan tertutup untuk mencegah kerusakan terhadap objek jika terjadi kerusakan lampu. Jika pencahayaan ruangan baik, karya seni pun menampilkan efek yang cukup, maka hasil untuk pembelajaran seni pada galeri tersebut juga maksimal serta memberikan kenyamanan bagi yang melihatnya. Penelitian ini dilakukan dengan teknik kualitatif di mana peneliti ikut aktif dalam merasakan pencahayaan terhadap tampilan karya seni di Roemah Seni Sarasvati. Tujuan dari penelitian ini adalah untuk menganalisis jenis pencahayaan yang digunakan di Roemah Seni Sarasvati dan memberikan solusi standar pencahayaan buatan sehingga dapat diketahui kelebihan dan kekurangan dari pencahayaan yang digunakan.
\end{abstract}

Kata kunci: galeri Seni, pencahayaan, karya seni

Abstract: Art gallery is a room or building where artworks are exhibited. Gallery is a venue for exhibitions that is entertaining, recreational, and a media of appreciation of various artists, both local and foreign. This study was conducted in Roemah Seni Sarasvati, Bandung, West Java, a gallery which is located on Jl. Sudirman 137, Bandung, this study refers to the effects of artificial lighting on artwork display at Roemah Seni Sarasvati. Roemah Seni Sarasvati is main project of Sarasvati Arts Management built to introduce the diversity of art and culture. The lighting at Roemah Seni Sarasvati is rather dim on artworks and at non-displaying room such as lounge or along circulation to other spaces. Various information saying that artificial lighting is better than natural lighting because artificial lighting which does not damage the light from existing artwork rather than direct light from the ultraviolet rays. This can be done by providing artificial light with a certain dimming to reduce the effects of UV radiation. In most art galleries, lighting in exhibition areas and other collection areas should have UV shield and covered to prevent damage to the object in case the lamp is broken. If the room lighting is good and the artwork displays considerable effect then art learning process shall be optimal and provide comfort to viewer. This research was 
conducted with qualitative techniques where researcher is actively participating in sensing lighting on artwork display at Roemah Seni Sarasvati. The purpose of this study was to analyze the type of lighting used in Roemah Art Sarasvati and provide a standard solution for artificial lighting so that can know the advantages and disadvantages of the lighting used.

Keywords: gallery Art, artificial lighting,

\section{Pendahuluan}

\subsection{Latar Belakang}

Banyak orang senang datang ke galeri seni hanya untuk hiburan, melepaskan penat, dan mencari ide. Seni adalah suatu gambaran atau karya yang memiliki beragam bentuk, contohnya seperti seni tari, seni lukis, seni ukir, seni instalasi, dan karya-karya lainnya yang bersifat seni. Kota yang terkenal dengan seninya adalah Kota Bandung. Di kota ini terdapat banyak galeri seni, sebagai contoh adalah Galeri Roemah Seni Sarasvati sehingga bisa diasumsikan warga Bandung memiliki cita rasa seni yang tinggi.

Survei, analisis, dan penjelasan dari buku membuktikan bahwa sarana dalam galeri yang terpenting adalah pencahayaan. Pencahayaan penting untuk memberikan suatu informasi dan penglihatan terhadap karya seni yang dipamerkan. Pencahayaan ruang ke ruang di Roemah Seni Sarasvati harus memiliki pencahayaan yang cukup agar tidak merusak karya seni tersebut, mempelihatkan karya seni dengan jelas, dan menerangi jalan, lorong ataupun ruang-ruang pamer karena pengunjung akan merasa segan dan takut jika alur tiap ruang memiliki cahaya yang temaram. Berdasarkan latar belakang tersebut penelitian ini dilakukan untuk menganalisis jenis pencahayaan yang digunakan di Roemah Seni Sarasvati dan memberikan solusi standar pencahayaan buatan sehingga dapat diketahui kelebihan dan kekurangan dari pencahayaan yang digunakan.

Data penelitian dikumpulkan melalui studi literatur, observasi, dokumentasi, dan wawancara. Metode tersebut dilakukan untuk mengetahui perilaku penggguna dan pengunjung terhadap kondisi pencahayaan galeri di Roemah Seni Sarasvati, sehingga dapat memperoleh gambaran tentang kekurangan dan kelebihan pada pencahayaan di galeri tersebut dan mengetahui pencahayaan yang sesuai untuk sebuah galeri.

\subsection{Fenomena Objek Studi}

Galeri Roemah Seni Sarasvati hanya terdiri dari dua lantai. Di ruangan bagian depan, yang dipajang adalah lukisan gaya Bali karya seorang pelukis dari Bali, di ruangan dalam terdapat foto-foto hitam putih dan lukisan kontemporer, di area dekat tangga ada kamera-kamera dari tahun 1800-an, dan di lantai dua tidak terlalu banyak karya seni yang dipajang. 


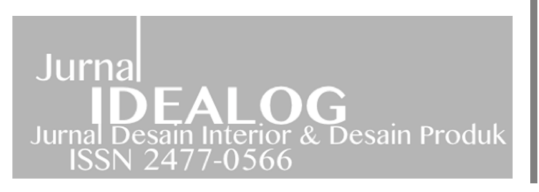

Pencahayaan buatan yang terdapat di ruang tengah tidak terlalu terang, cahaya hanya membei efek remang pada benda pameran dan suasana ruangan. Pada lantai atas, pencahayaan kurang terang, yang dapat memengaruhi penglihatan manusia saat melihat benda pameran, apalagi jika pameran berlangsung hingga malam hari.

\section{Kajian Literatur}

\subsection{Standar Pencahayaan Galeri}

Dalam tampilan visual, diperlukan identifikasi bidang kerja yang bertujuan untuk menentukan karakteristik pencahayaan buatan (Iesna, 2000:127)

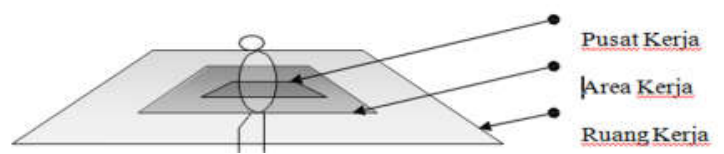

Gambar 2.1 Prioritas Daerah Kerja

Sumber: Fordergemeinscaft Gutes Licht (2008:5)

Beberapa faktor yang perlu dihindari untuk mendapatkan kenyamanan penglihatan pada bidang kerja, dalam Iesna (2000:127)

1. Silau (Glare)

Memiliki dua buah silau disability glare dan discomfort glare. Disability Glare adalah silau yang menyebabkan mata tidak mampu melihat apa pun akibat dari pancaran sinar yang besar ke arah mata. Discomfort Glare adalah silau yang ditimbulkan akibat pantulan sinar terhadap bidang kerja atau unsur-unsur di sekitarnya yang menuju mata.

2. Bayangan (Shadow)

Pancaran sinar cahaya ke bidang kerja tertutupi oleh suatu objek (tangan).

3. Cahaya Kejut (Flicker)

Ketidakstabilan suplai cahaya yang dihasilkan sumber cahaya yang menyebabkan perubahan intensitas cahaya dengan cepat.

\subsection{Tinjauan Umum Desain Pencahayaan Buatan dalam Perancangan Interior Galeri}

Cahaya buatan memiliki sistem penerangan tersendiri yang bertujuan untuk tercapainya efektivitas dan efisiensi pemanfaatan cahaya buatan di dalam ruangan. Sistem cahaya buatan dibagi menjadi 2, yaitu:

1. Sistem Lighting Primer

a. General Lighting (Down lighting): sistem pencahayaan umum, merata di semua ruangan.

b. Localized Lighting (Free Standing Up Lighter): Sistem pencahayaan yang mempunyai penataan khusus untuk mendukung aktivitas di area tertentu.

c. General Lighting dan Localized Lighting: Sistem ini digunakan dalam ruangan yang membutuhkan intensitas cahaya dengan lux tertentu.

2. Sistem Lighting Sekunder

a. Ambient Light: sistem penerangan dengan sinar merata (difuse). 
b. Accent Light: sistem penerangan yang sinarnya berfungsi sebagai aksen.

c. Task Light: sistem penerangan yang sinarnya bertujuan fungsional, misalnya untuk membaca.

d. Effect Light: sistem penerangan yang menyerupai accent light, tetapi obyek dan cahaya menjadi pusat perhatian.

e. Decorative Light: sistem penerangan yang bentuknya sebagai unsur dekoratif interior dengan intensitas dan warna cahaya untuk menciptakan suasana.

f. Architecture Light: sistem penerangan dengan cahaya sebagai media pendukung olahan atau karya arsitektur (disebut juga structural light).

Teknik pengaturan pencahayaan buatan antara lain:

\section{High Lighting}

Memberikan sorotan cahaya pada karya seni tertentu untuk mempertajam detail dan warna karya seni.

2. Wall Washing

Memberikan suatu lapisan pencahayaan pada bidang dinding agar dinding terkesan merata dengan cahaya.

3. Silhouetting

Menempatkan karya seni di antara bidang tangkap cahaya agar karya seni terlihat sebagai suatu bentuk bayangan.

4. Beam Play

Memanfaatkan sorotan cahaya sebagai elemen visual.

5. Shadow Play

Menonjolkan bayangan hasil sorotan cahaya sebagai elemen visual.

6. Sparkle

Menjadikan sumber cahaya sebagai elemen visual.

\subsection{Pencahayaan untuk Efek Karya}

Dalam sistem pencahayaan buatan, ada teknik pembagian berkas cahaya atau distribusi cahaya. Berkas cahaya tersebut berasal dari armature lampu. Armature lampu memiliki beragam jenis, yaitu:

\section{Indirect}

Armatur ini mengarahkan lebih dari 90\% cahaya ke atas dengan memanfaatkan langit-langit sebagai pemantul. Dipakai pada bidang yang mempunyai daya reflektansi cukup besar.

2. Semi Indirect

Armatur ini menyerupai jenis armature indirect, lebih dari 60\% cahaya lampu diarahkan ke atas, sekaligus mengarahkan $40 \%$ cahaya ke bawah.

3. Semi Direct

Armatur ini mengarahkan cahaya yang sama kuatnya ke arah atas dan arah bawah.

4. Direct

Armatur ini mengarahkan cahaya lebih dari 90\% ke arah bawah.

5. Diffused

Armatur ini menyebarkan cahaya secara merata ke segala arah. 

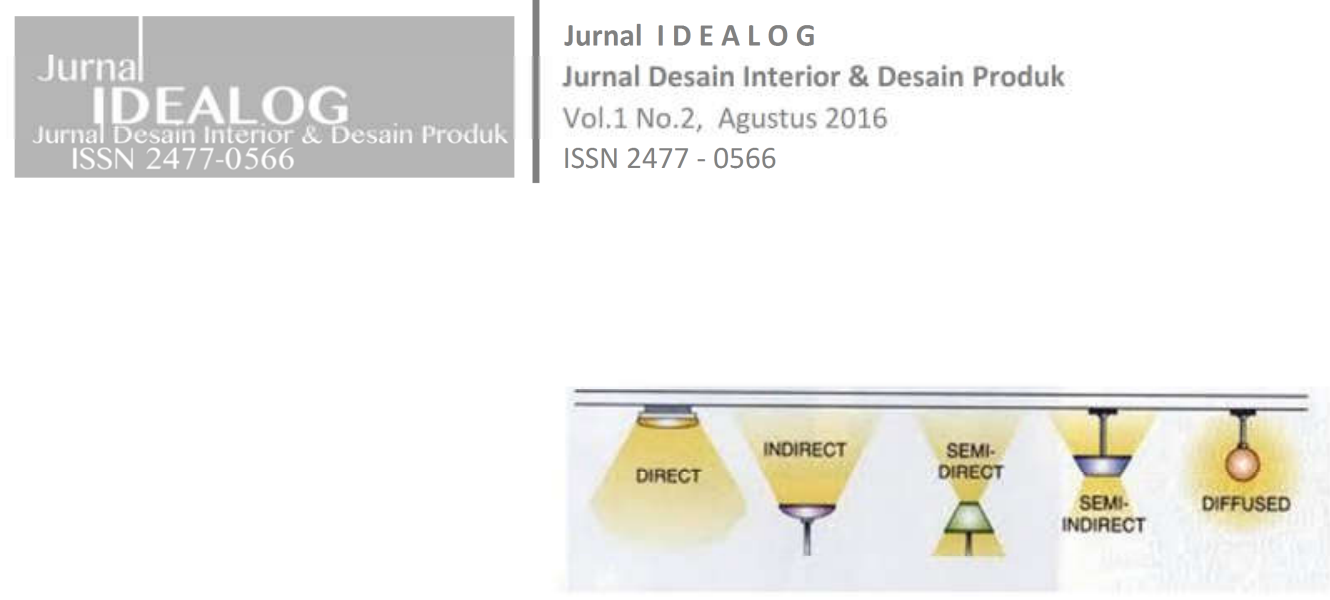

Gambar 2.2 Lima Teknik Pendistribusian Cahaya Sumber: Philips Methods of light dispersement

\section{Metode Penelitian}

Penelitian ini menggunakan metode kualitatif. Penelitian kualitatif ini dalam pengumpulan data menggunakan teknik survei, yaitu melihat secara langsung kondisi di galeri Roemah Seni Sarasvati dengan perbandingan teori yang ada, mengamati suasana dan perilaku pengunjung, serta mencatat fenomena yang ada.

Teknik pengumpulan data penelitian ini juga menggunakan metode observasi dan studi literatur. Metode observasi ini dilakukan di galeri Roemah Seni Sarasvati mengenai pencahayaan buatan untuk area pamer dan studi literatur sebagai teori-teori pendukung pada penelitian ini.

Proses awal yang dilakukan pada penelitian ini dengan mengumpulkan data valid berdasarkan hasil survei, observasi dan studi literatur yang sudah dilakukan untuk memperkuat penelitian, kedua melakukan pengelohan data, ketiga melakukan analisa penelitian yang bertujuan untuk mencapai kesimpulan dari penelitian yang dilakukan dan menjawab pertanyaan dari penelitian tersebut.

\section{Pembahasan}

\subsection{Hasil Survei Pencahayaan Buatan di Area Pamer Roemah Seni Sarasvati}

Area pamer di ruang A (lantai 1) terdiri dari dua area: area pamer depan (memiliki hubungan langsung dengan pintu masuk) dan area pamer tengah. Sebagian besar karya Sarasvati yang dipamerkan di ruang ini merupakan karya dua dimensi, yaitu lukisan. Ruang A (lantai 1) area pamer depan tidak memiliki jendela karena bangunan ini diapit kanan kiri oleh bangunan lain. Maka dari itu pencahayaan alami hanya didapatkan dari arah cahaya pintu utama yang terbuka. 

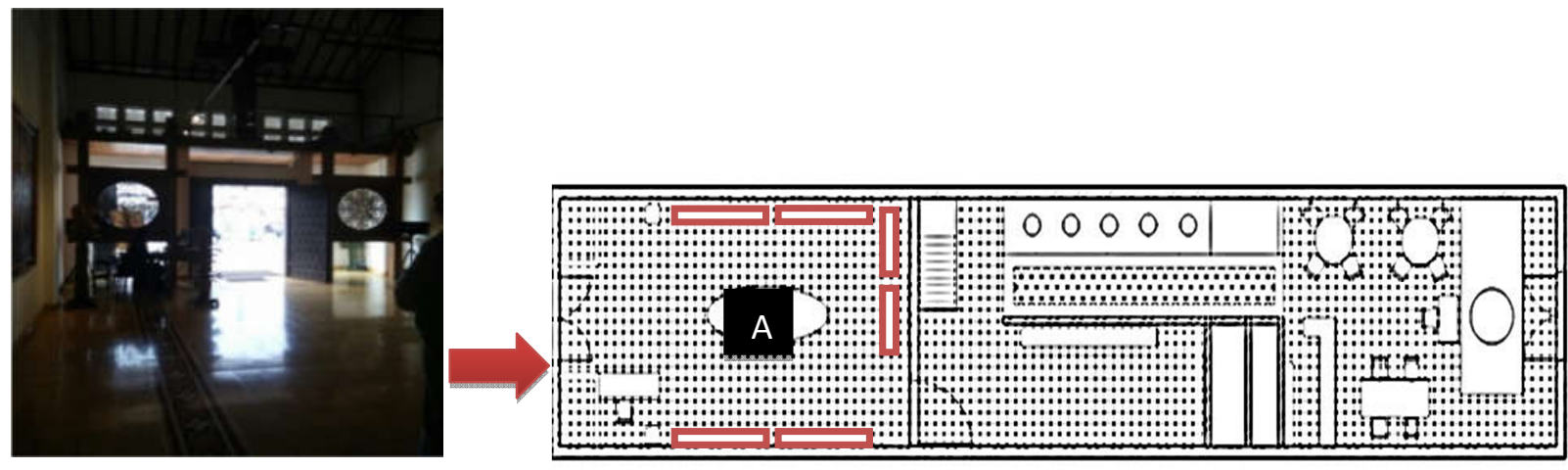

Gambar 4.1 Letak karya lukisan di arah depan/pintu masuk Ruang A (lantai 1) Sumber: Dokumentasi penulis

Area pamer tengah di ruang A1 (lantai 1) merupakan sebuah ruang yang tidak terlalu besar. Begitu masuk ke area tengah ini, perhatian pengunjung langsung tertuju pada dinding depan dan dinding bagian kanan. Di sana terdapat karya dua dimensi berupa seni fotografi. Area pamer tengah ini memiliki dinding kaca di bagian kiri, yang di balik kaca tersebut terdapat sebuah taman yang mengarah ke ruang cafe (area belakang). Pencahayaan menggunakan track lamp dengan sistem primary lighting: localized lighting dan sistem secondary lighting: accent lighting. Teknik pengaturan pencahayaan highlighting, dan jenis armatur lampu direct.

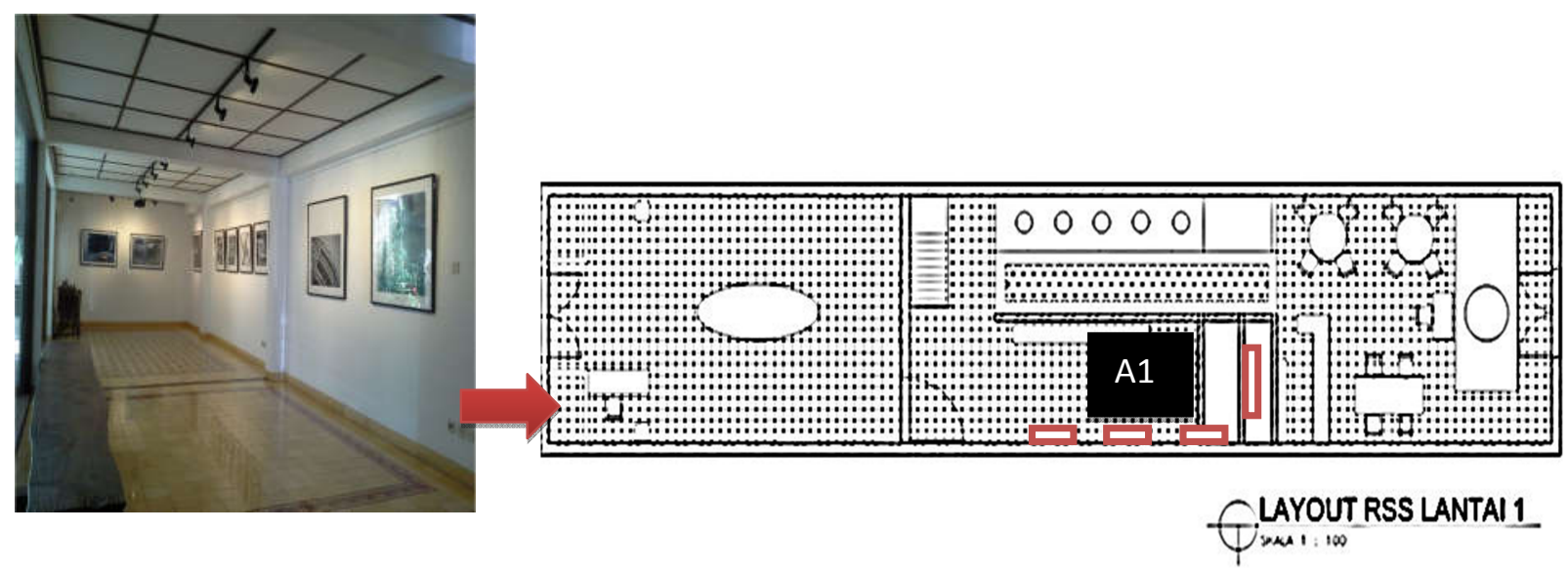

Gambar 4.2 Letak karya lukisan di area pamer tengah, Ruang A1 (lantai 1)

Sumber: Dokumentasi penulis 
Area pamer atas di ruang B (lantai 2) merupakan sebuah ruang pamer yang menampilkan karya dua dimensi berupa lukisan. Di ruang ini pencahayaan buatan tidak terang, jenis lampu yang digunakan adjustable tubular spotlight dengan 1 lampu menerangi 1 karya seni dan lebih menggunakan pencahayaan alami di siang hari. Pada area ini terdapat hotel khusus seniman.
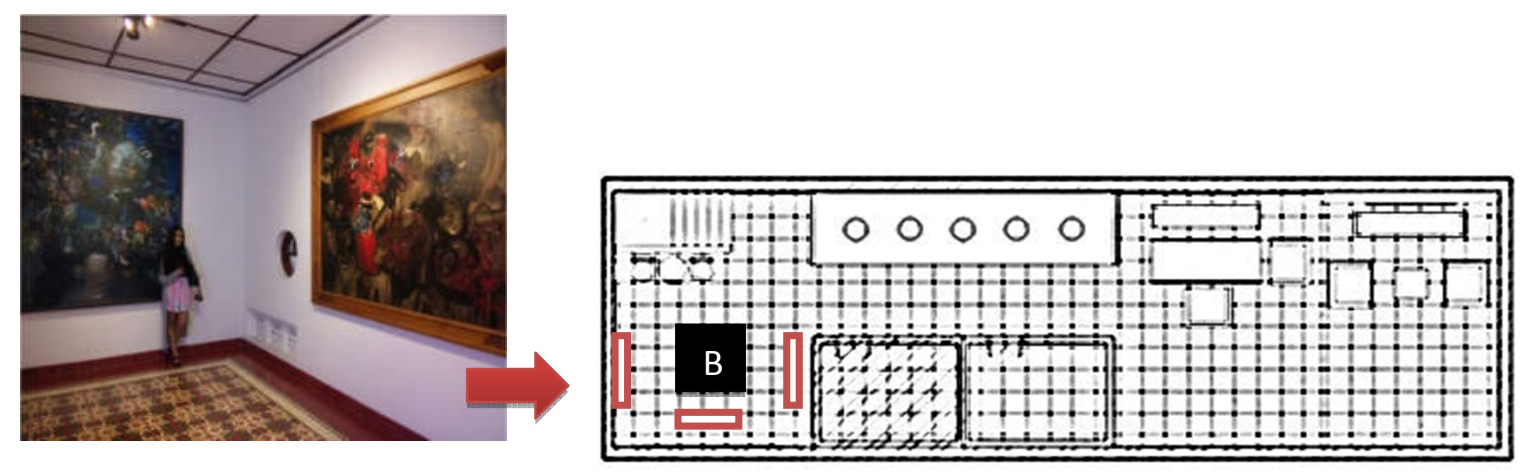

LAYOUT RSS LANTAI 2 ians.'. is

Gambar 4.3 Letak karya lukisan di area pamer atas, Ruang B (lantai 2)

Sumber: Dokumentasi penulis

Tabel 1.1 Teknik Pencahayaan pada Roemah Seni Sarasvati

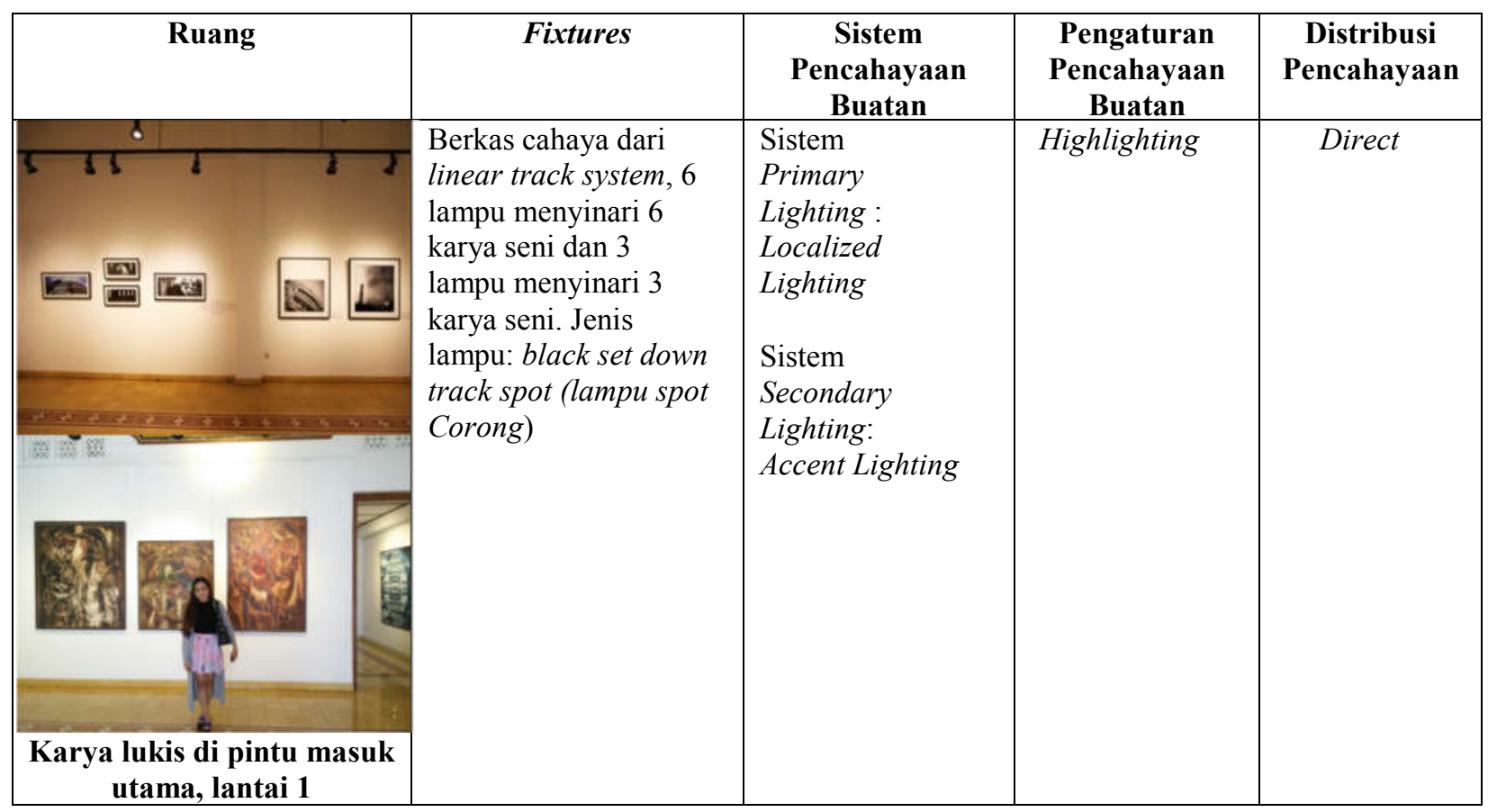




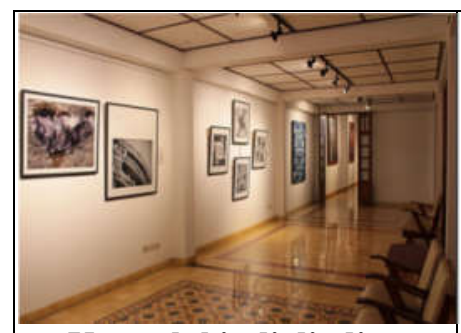

Karya lukis di dinding

Kanan (dari arah pintu masuk ruang utama), lantai 1

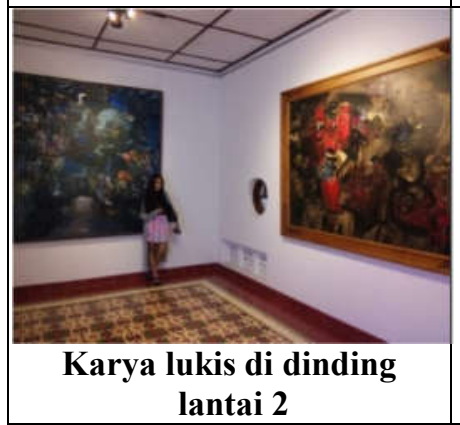

Berkas cahaya dari linear track system, 1 lampu menyinari 1 karya seni, dan 4 lampu menyinari 4 karya seni. Jenis lampu: black set down track spot.

\section{Berkas cahaya dari} linear track system, 1 lampu menerangi 1 karya seni. Jenis lampu: adjustable tubular spotlight.

\begin{tabular}{|l|l|l|}
\hline Sistem & Highlighting & Direct \\
Primary & & \\
Lighting: & & \\
Localized & & \\
Lighting & & \\
& \\
Sistem & & \\
Secondary & & \\
Lighting: & & \\
Accent & & \\
Lighting & Highlighting & Direct \\
Sistem & & \\
Primary & & \\
Lighting: & & \\
Localized & & \\
Lighting & & \\
Sistem & & \\
Secondary & & \\
Lighting: & & \\
Accent & & \\
Lighting & & \\
\hline
\end{tabular}

Sumber: Analisis penulis

\subsection{Ruang Pameran}

Roemah Seni Sarasvati memiliki lebar 6,5 meter dengan tinggi sekitar 4 meter di ruang utama, dan sekitar 3 meter di ruang pamer selanjutnya, terutama di lantai 2. Standar tinggi minimum dari dinding display adalah 3.7 meter. Ukuran tinggi ini digunakan oleh kebanyakan museum/galeri seni. Seni kontemporer membutuhkan tinggi plafon sampai 6 meter sebagai tinggi yang fleksibel bagi pameran seni.

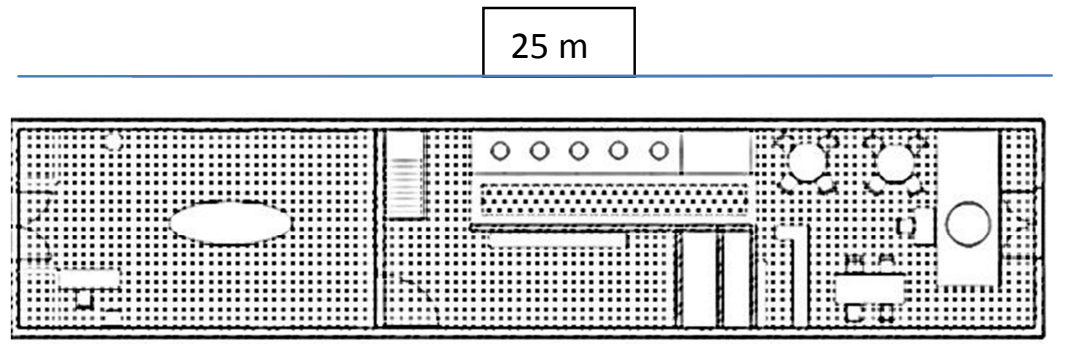

\section{$6,5 \mathrm{~m}$}

Gambar 4.4 Denah

Roemah Seni Sarasvati

Sumber: Analisis penulis
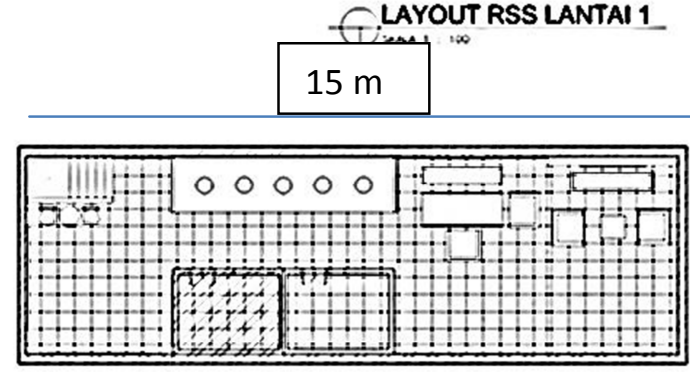
Gambar 4.5 Denah Titik Lampu Roemah Seni Sarasvati

Sumber: Analisis penulis
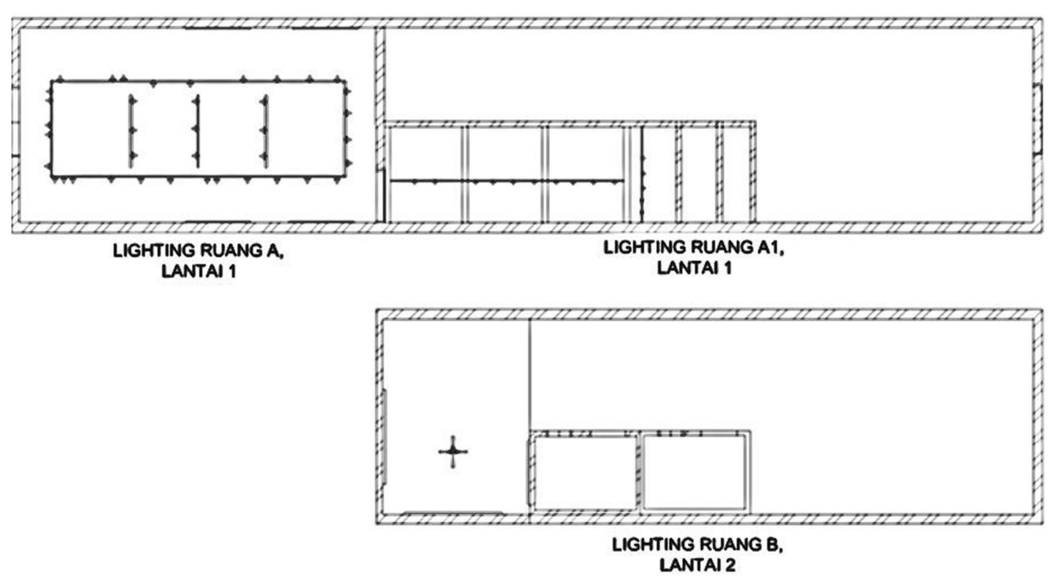

\subsection{Galeri Sarasvati}

4.3.1 Foto-Foto dengan Suasana Pencahayaan Galeri di Roemah Seni Sarasvati pada Siang Hari

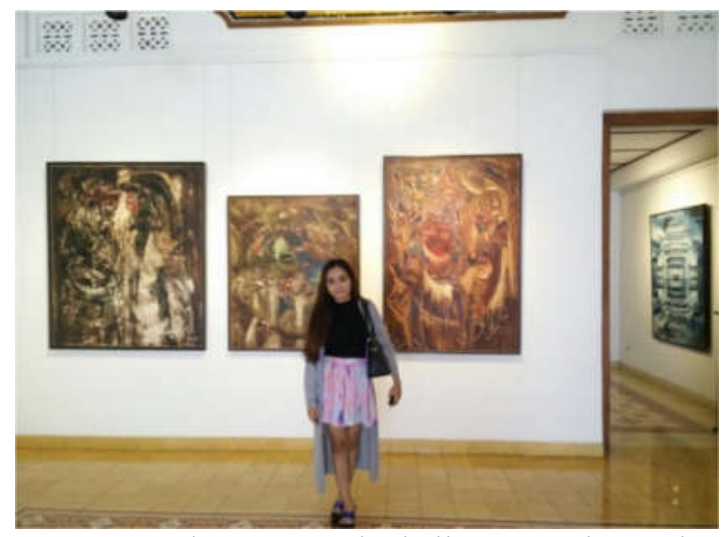

Gambar 4.6 Suasana pencahayaan galeri di Roemah Seni Sarasvati Lantai 1, Pintu Masuk

(Dokumentasi Penulis, 2015)

Pada foto ini, pencahayaan terlihat terang. Jika berada langsung di lokasi, pencahayaan terasa_kurang terang karena penerangan pada siang hari memanfaatkan pencahayaan alami sehingga menimbulkan banyak bayangan di sekitarnya. 

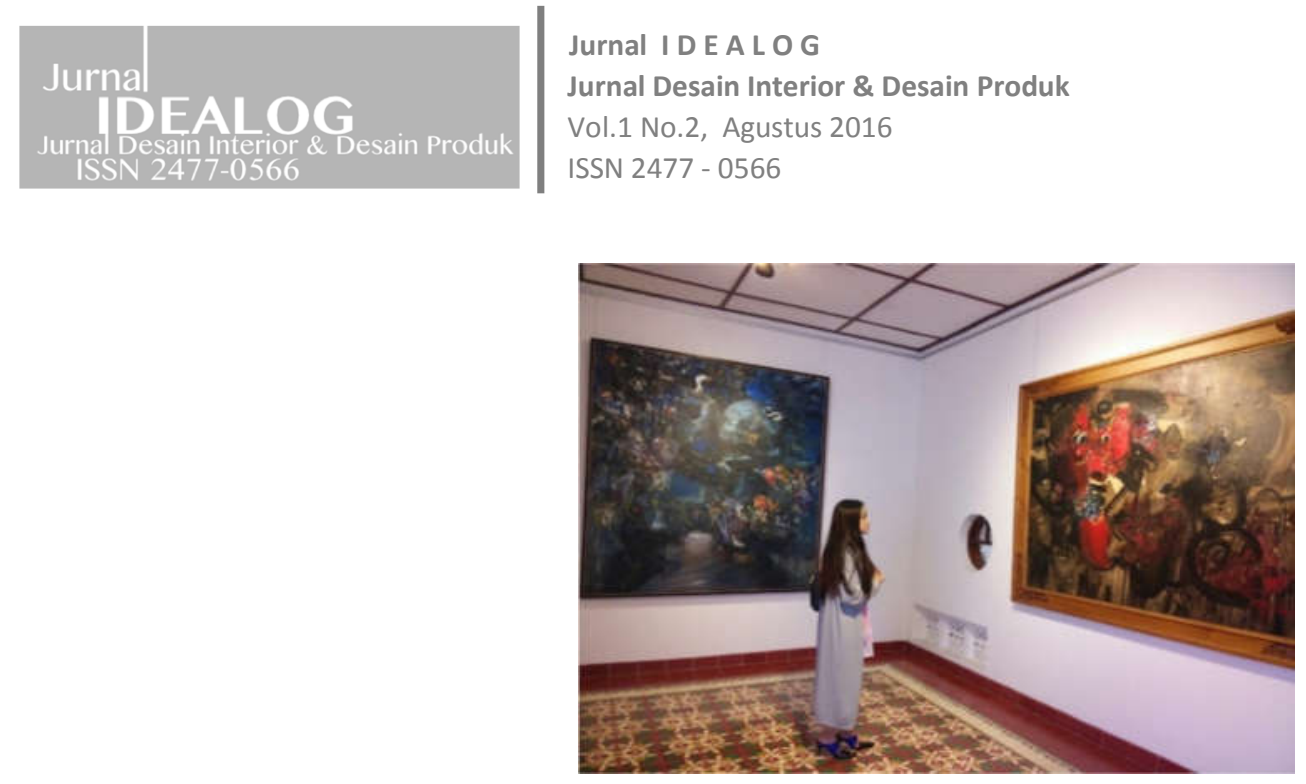

Gambar 4.7 Suasana pencahayaan yang tidak terang pada galeri di Roemah Seni Sarasvati Lantai 2

(Dokumentasi Penulis, 2015)

Pada area pamer atas, ruang B (lantai 2) pencahayaan menggunakan 3 lampu untuk 3 karya seni yang berukuran besar. Foto ini diambil pada siang hari sehingga terbantu oleh pencahayaan buatan yang terdapat di lantai atas.

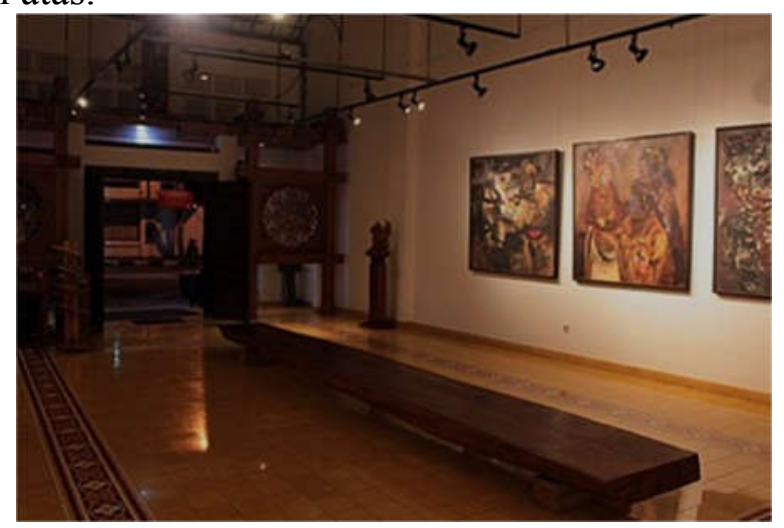

Gambar 4.8 Suasana pencahayaan yang gelap pada galeri di Roemah Seni Sarasvati Lantai 1

(Dokumentasi Penulis, 2015)

Foto ini terletak di area utama pintu masuk. Bisa dilihat bahwa pencahayaan terlihat gelap dan memaksimalkan pencahayaan dari arah pintu masuk dan spotlight. Peletakkan lampu track di area ini kurang dekat dengan karya seni sehingga efek pencahayaan buatan terhadap karya seni yang dipamerkan kurang maksimal. 


\subsubsection{Foto-Foto Suasana Pencahayaan Galeri di Roemah Seni Sarasvati pada Malam Hari.}
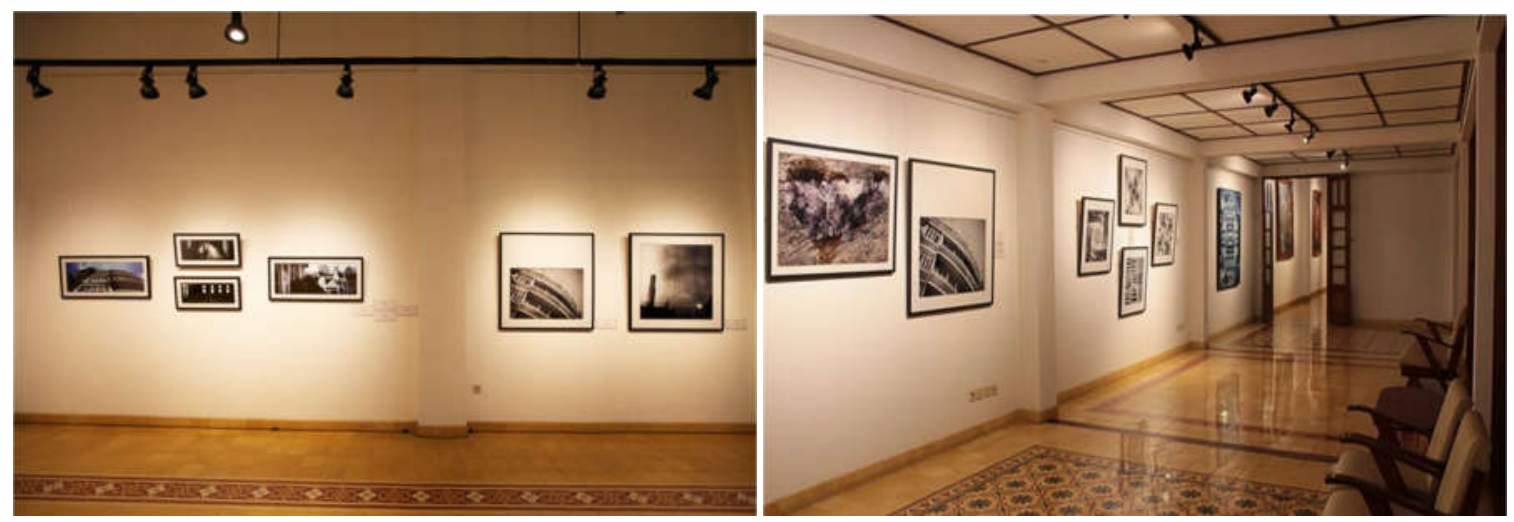

Gambar 4.9 Suasana pencahayaan yang gelap pada area duduk dan sekitar di galeri Roemah Seni Sarasvati Lantai 1 (Dokumentasi Penulis, 2015)

Pada pencahayaan area tengah di lantai 1, setiap karya seni yang dipamerkan memiliki 1 lampu yang menyinari. Dilihat dari standar pencahayaan yang digunakan, sudah sesuai karena pencahayaan tidak berlebihan, sehingga tidak merusak karya seni yang ada. Pada siang hari, area ini terbantu dengan pencahayaan alami yang dibatasi oleh kaca di seberang kanan (jika dilihat dari foto ini). Jika malam hari, area tersebut hanya dibantu oleh sinar dari lampu sorot yang mengenai karya seni. Kekurangan pencahayaan pada area ini adalah, seharusnya terdapat pencahayaan general yaitu general lighting (downlight/hanging lamp/TL/LED) untuk menyinari area jalan pengunjung, ataupun penyinaran ke area-area selanjutnya, terutama ruang tunggu.

\subsection{Analisis Penelitian}

Secara perletakan lokasi, Galeri Roemah Seni Sarasvati diapit oleh gedung-gedung bangunan yang secara tidak langsung pencahayaan sulit masuk ke area tersebut. Faktor dari gaya bangunan art deco di Galeri Roemah Seni Sarasvati juga memengaruhi suasana area pamer, sehingga memberikan kesan sunyi dengan pencahayaan buatan yang juga kurang maksimal. Area pamer di ruang utama Roemah Seni Sarasvati tidak menggunakan sistem primary lighting. Lighting primer adalah teknik pencahayaan buatan yang digunakan dalam perancangan interior galeri berupa General Lighting dan Localized Lighting. Ruangan ini secara keseluruhan mengandalkan sistem secondary lighting, berupa accent lighting untuk karya seninya. Hal ini karena galeri memanfaatkan sumber cahaya alami dari pintu utama masuk ke dalam area pamer tersebut. Teknik pengaturan pencahayaan ruang pamer menggunakan highlighting, sedangkan distribusi pencahayaannya menggunakan distribusi pencahayaan direct. 
Pencahayaan pada galeri Roemah Seni Sarasvati kebanyakan berkas cahaya dari linear track system, dengan satu lampu menyinari 1 karya seni dengan jenis lampu black set down track spot (lampu spot Corong) dan adjustable tubular spotlight. Pengaturan pencahayaan buatan pada ruang pamer menggunakan High Lighting, yaitu dilakukan dengan memberikan sorotan cahaya pada obyek tertentu. Teknik pembagian berkas cahaya semua memakai pencahayaan Direct, armatur jenis ini mengarahkan cahaya lebih dari 90\% ke arah bawah.

\subsubsection{Analisis Titik Lampu}

Teori utama yang perlu dipelajari dari pencahayaan galeri adalah banyaknya titik lampu, ini adalah standar penerangan yang menjadi prasyarat dan fungsi galeri. Banyaknya titik lampu tersebut bergantung pada intensitas cahaya dan warna cahaya (Cahyana, dkk., 2010:35-37).

Dari analisis yang telah dilakukan berdasarkan teori yang digunakan, lokasi yang diteliti memiliki pencahayaan yang mengaplikasikan pencahayaan paralel di tiap-tiap karya yang ada. Hal ini harus diatasi karena penggunaan lampu sorot pada galeri ini kurang memenuhi standar yang ada, yaitu permasalahan jarak lampu ke objek pameran (lampu sorot yang efektif mengarah pada pusat dari objek yang dipamerkan dengan sudut perlengkapan lampu yang dipasang sekitar 1 meter, di mana pusat dari objek tersebut dipasang di bawah sumber cahaya). Penggunaan jenis lampu sorot yaitu track lighting spotlight dan posisi lampu yang menghadap ke arah karya seni pada galeri ini sudah benar, tetapi jarak lampu terhadap karya seni seharusnya juga diperhatikan (jarak lampu ke karya di Roemah Seni Sarasvati adalah sekitar 1,5 meter).

\subsubsection{Analisis Luminair Track}

Menurut Mark Karlen \& James Benya (2006), luminair track harus ditempatkan secara paralel untuk seluruh permukaan benda yang dipamerkan, dan pada jarak yang cukup jauh untuk memungkinkan perubahan arah cahaya pada sudut 30 derajat dari garis vertikal untuk menerangi benda seni yang digantung pada ketinggian pandangan mata. Pemasangan jarak luminair track pada galeri Roemah Seni Sarasvati sudah dapat dibilang hampir sempurna, sesuai dengan teori dari Mark Karlen \& James Benya (2006), pemasangan tersebut sudah ditempatkan secara paralel, tetapi dengan jarak yang terlalu jauh. Hal ini telah menggambarkan bahwa penggunaan lampu yang cocok untuk galeri yaitu luminair track, meskipun tetap memperhatikan faktor-faktor lain, | yaitu warna dan jumlah lampu yang seharusnya diaplikasikan pada sebuah pameran karya seni. 


\section{Hasil Pembahasan}

Dari hasil penelitian "EFEK PENCAHAYAAN BUATAN TERHADAP TAMPILAN KARYA DI ROEMAH SENI SARASVATI“ ditemukan bahwa:

1. Area pamer di ruang utama Roemah Seni Sarasvati tidak menggunakan sistem lighting primer. Ruangan ini secara keseluruhan mengandalkan sistem lighting secunder, berupa accent lighting untuk karya seninya. Hal ini terjadi karena galeri memanfaatkan sumber cahaya alami dari pintu utama masuk ke dalam area pamer tersebut. Teknik pengaturan pencahayaan ruang pamer menggunakan highlighting, sedangkan distribusi pencahayaannya menggunakan distribusi pencahayaan direct.

2. Pencahayaan pada galeri Roemah Seni Sarasvati kebanyakan menggunakan berkas cahaya dari linear track system, satu lampu menyinari satu karya seni dengan jenis lampu black set down track spot (lampu spot Corong) dan adjustable tubular spotlight. Pengaturan pencahayaan buatan pada ruang pamer menggunakan High Lighting, yaitu dilakukan dengan memberikan sorotan cahaya pada objek tertentu. Teknik pembagian berkas cahaya semua memakai pencahayaan Direct, armature lampu jenis ini mengarahkan cahaya lebih dari $90 \%$ ke arah bawah.

3. Setiap ruang ini menerapkan pencahayaan yang sama dan secara keseluruhan pencahayaan yang ada difokuskan untuk menerangi benda-benda koleksi yang dipamerkan dan penataannya rapi.

\section{Kesimpulan}

Berdasarkan analisis penulis, dapat disimpulkan bahwa Roemah Seni Sarasvati tidak menggunakan sistem lighting primer pada area pamer, tetapi menggunakan lighting secunder, mengaplikasikan pencahayaan paralel di tiap-tiap karya, dan jarak lampu ke karya di Roemah Seni Sarasvati adalah sekitar 1,5 meter. Ruang pamer utama, dengan posisi yang berada di lantai 1, pencahayaan alami yang masuk lebih dominan sehingga pada siang hari pencahayaan alami menjadi general lighting, sedangkan pencahayaan alaminya pun terhambat dengan arah jalan raya, dan pencahayaan buatan yang ada hanya digunakan untuk menyinari benda koleksi. Ruang pamer tengah lantai 1, sumber cahaya alami sedikit masuk dari arah lantai 2, sehingga pencahayaan dari lampu-lampu menjadi pencahayaan general pada ruangan ini, dan pencahayaannya kurang maksimal serta konsep visualnya (sinar) sama saja. Ruang atas lantai 2, ruangan ini lebih redup karena koleksinya yang sedikit memengaruhi spotlight yang digunakan juga sedikit dan tanpa general lighting, hanya dibantu sedikit dengan pencahayaan alami pada siang hari. Seharusnya gedung bersejarah ini memiliki sistem pencahayaan penerangan yang maksimal dan standar jarak yang sesuai, tidak hanya objek yang diterangi, tetapi sirkulasi jalan dari satu ruang menuju ruang lain juga ditambahkan cahaya lampu general lighting, sehingga pengunjung tidak merasa bosan, sunyi dan dapat betah melihat pameran sembari bersosialisasi di area cafe. Secara keseluruhan, seluruh ruang menggunakan pencahayaan buatan dan jarak yang 


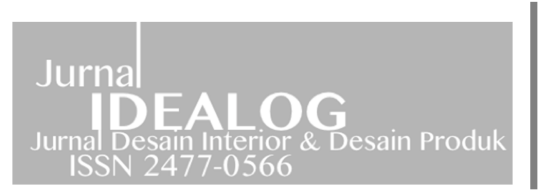

kurang seimbang sehingga area pamer menjadi kurang maksimal, tetapi untuk penggunaan jenis lampu, karya seni yang dipamerkan dan area cafe sudah memuaskan.

\section{Daftar Pustaka}

[1] Cahyana, Agus., Wieke Tasman, \& Irfan Nurachman. (2010). Kesejarahan Bagai Tema Display Pada Museum di Ubud Bali. Universitas Kristen Maranatha. http://repository.maranatha.edu (diakses tanggal 12 November 2015)

[2] Cuttle, Christopher. (2008). Lighting By Design. Oxford: Architectural Press.

[3] Descottes, Herve. (2005). Ultimate Lighting Desain. Italy: teNeues Publishing Group.

[4] Karlen, Mark \& James Benya. (2007). Dasar-Dasar Desain Pencahayaan. Jakarta: Erlangga.

[5] Karlen, Mark \& James Benya. (2007). Dasar-Dasar Perencanaan Ruang. Jakarta: Erlangga.

[6] Martin, Lucy.(2010). The Lighting Bible. London: Quarto Publishing plc.

[7] Notebook, DI. (2013). Isi Lighting. Universitas UNIKOM. http://di.unikom.ac.id/isi lighting.pdf (diakses tanggal 17 November 2015).

[8] Pile, John F.(1988). Interior Design. New York: Harry N. Abrams, Incorporated. 